\title{
DEVELOPMENT AND EVALUATION OF TIZANIDINE HYDROCHLORIDE LOADED SOLID LIPID NANOPARTICLES
}

\author{
PAVITHRA K, BHAGAWATI ST*, MANJUNATH K \\ Department of Pharmaceutics, Sree Siddaganga College of Pharmacy, Tumkur, Karnataka, India. Email: stbhagawati@rediffmail.com
}

Received: 11 June 2019, Revised and Accepted: 16 August 2019

ABSTRACT

Objectives: The primary objective of the present study is to develop and evaluate tizanidine hydrochloride (TZ) solid lipid nanoparticles (SLNs) using solid lipids/triglycerides.

Methods: TZ SLNs were prepared by hot homogenization followed by ultrasonication technique. The prepared SLNs were characterized for drug content, entrapment and loading efficiency, particle size, zeta potential, polydispersity index (PDI), and in intro release kinetics.

Results: TZ SLNs were prepared. The particle size ranged from 49.7 to $523.7 \mathrm{~nm}$. PDI of all formulations was good within the range of $0.189-0.487$. The zeta potential of blank SLNs was $-15.2 \mathrm{mV}$ whereas drug-loaded SLNs showed zeta potential from $-8.85 \mathrm{mV}$ to $-42.0 \mathrm{mV}$. Entrapment efficiency observed was in the range of 34.5-75.0\%. The cumulative percentage release of TZ from different TZ nanoparticles varied from 35.28\% to 83.98\% depending on the drug-lipid ratio and the type of lipid and surfactant used. The release kinetic studies of optimized formulation showed that the release was first order and the release mechanism was non-Fickian type.

Conclusion: The prepared SLNs were able to sustain the drug release for $24 \mathrm{~h}$, thus reducing dosing frequency and occurrence of side effects, thereby increasing the effectiveness of the drug.

Keywords: Tizanidine hydrochloride, Solid lipid nanoparticles, Hot homogenization, Ultrasonication, Fourier-transform infrared spectroscopy, In vitro drug release.

(C) 2019 The Authors. Published by Innovare Academic Sciences Pvt Ltd. This is an open access article under the CC BY license (http://creativecommons. org/licenses/by/4. 0/) DOI: http://dx.doi.org/10.22159/ajpcr.2019.v12i10.34545

\section{INTRODUCTION}

Most of the people prefer oral route of administration as the major route of administration of pharmaceuticals having the advantage of being painfree, convenient to handle, and noninvasive [1]. However, the oral dosage form has several disadvantages. To overcome the disadvantages of the oral route of administration, many new powerful drug substances have been found due to new technologies employed in drug discovery. Solid lipid nanoparticles (SLNs) are the novel drug delivery system in which the active drug is incorporated into lipid carriers with the help of the stabilizers. They are solid colloids having the size in nanometers that range from 10 to $1000 \mathrm{~nm}$ at least in one dimension (generally 50-500 nm) [2]. SLNs combine the advantages of and simultaneously avoid the limitations of polymeric nanoparticles, fat emulsions, and liposomes [3].

Spasticity or increased tone is the tightness that patients report with passive movement of the limb. In more scientific language, spasticity is a motor disorder characterized by a velocity-dependent increase in the tonic stretch reflex [4]. Tizanidine is an agonist at $\alpha 2$-adrenergic receptor sites and presumably reduces spasticity by increasing presynaptic inhibition of motor neurons [5]. It acts mainly at the spinal cord level and is used for the symptomatic relief of spasticity associated with spinal cord injury or diseases or multiple sclerosis [6]. In the present study, we aim to develop tizanidine hydrochloride (TZ) loaded SLNs, which sustains the drug release thereby increasing the efficiency of the treatment.

\section{MATERIALS AND METHODS}

Materials

TZ was procured from the Swapnroop drug and pharmaceuticals, Ahmadabad. Tristearin (TS) was purchased from Sasol, Germany. Compritol 888 (CM) was obtained from Gattefosse, France. Glyceryl monostearate (GMS) was purchased from Research Lab Fine Chem Industries, Mumbai. Methanol, tween 80 (TW) and chloroform were purchased from SD Fine Chem Limited, Bengaluru. Soy lecithin (SL) and poloxamer 188 (PL) were obtained from HiMedia Laboratories Pvt., Ltd., Bengaluru. All the reagents used were of analytical grade.

\section{Methods}

Determination of $\lambda_{\text {max }}$ of TZ in phosphate buffer of $\mathrm{pH} 7.4$

Accurately weighed the quantity of $10 \mathrm{mg}$ of $\mathrm{TZ}$ was taken in $100 \mathrm{ml}$ volumetric flask and was dissolved using phosphate buffer of $\mathrm{pH} 7.4$ and the volume was made up to $100 \mathrm{ml}$ with phosphate buffer of $\mathrm{pH} 7.4$ to produce $100 \mu \mathrm{g} / \mathrm{ml}$ solutions. From the above stock solution, $10 \mu \mathrm{g} / \mathrm{ml}$ solutions were prepared and scanned between $200 \mathrm{~nm}$ and $400 \mathrm{~nm}$ by keeping phosphate buffer of $\mathrm{pH} 7.4$ as blank [7]. The absorption maxima of $320 \mathrm{~nm}$ for TZ was obtained and used for further studies.

\section{Preparation of calibration curve in phosphate buffer of $\mathrm{pH}-7.4$}

Accurately weighed quantity of $10 \mathrm{mg}$ of $\mathrm{TZ}$ was taken in $100 \mathrm{ml}$ volumetric flask and was dissolved in phosphate buffer of pH-7.4. Finally, the volume is made up to $100 \mathrm{ml}$ with phosphate buffer of $\mathrm{pH} 7.4$ to produce $100 \mu \mathrm{g} / \mathrm{ml}$ solutions (stock solution-I). $0.2,0.4,0.6,0.8$, 1.0 , and $1.2 \mathrm{ml}$ of stock solution-I were taken and transferred to $10 \mathrm{ml}$ volumetric flasks, and volume was made up to $10 \mathrm{ml}$ using phosphate buffer of pH 7.4 to get $2,4,6,8,10$, and $12 \mu \mathrm{g} / \mathrm{ml}$ solutions, respectively. The absorbance of these solutions was determined in ultraviolet (UV)spectrophotometer at $320 \mathrm{~nm}$, and the calibration curve was plotted [8].

\section{Preparation of SLNs with TZ using lipids (CM, TS, and GMS)}

SLNs were prepared using lipids (CM, TS, and GMS) and surfactants (TW and PL). Lipid was first melted by heating in a boiling tube and then SL and the drug was added to the lipid melt which was then heated to the temperature $5^{\circ} \mathrm{C}$ above the melting point of the lipid. Simultaneously, 
surfactant (PL/TW) was dissolved in water in a test tube and heated to a temperature equal to that of the lipid phase. This aqueous phase was transferred to the lipid phase in small quantities by continuous homogenization. This mixture was homogenized at 20,000 rpm for $5 \mathrm{~min}$ and then immediately placed in probe ultrasonicator at $75 \%$ amplitude for $30 \mathrm{~min}$. Blank nanoparticles were prepared in a similar manner omitting the $\mathrm{TZ}$ in the preparation [9]. The composition of all formulations is listed in Table 1.

\section{Evaluation of TZ SLNs}

\section{Fourier-transform infrared spectroscopy (FTIR)}

Drug-polymer interactions were studied by FTIR spectroscopy. Pure drug, excipients, and physical mixture of drug and excipients were subjected to FTIR studies. The spectra were recorded by scanning in the wavelength of $400-4000 \mathrm{~cm}^{-1}$ in an FTIR spectrophotometer [10].

\section{Differential scanning calorimetry (DSC)}

The melting point of the pure drug and compatibility of the drug with the lipids were studied by the DSC [11]. It was performed using Shimadzu DSC-60 by keeping the samples in aluminum crucibles.

\section{In vitro drug release study}

In vitro drug release studies were carried out in Franz diffusion cell. $2 \mathrm{ml}$ of nanoparticles dispersion was placed in donor compartment, while the receiver compartment consists of $22 \mathrm{ml}$ of diffusion medium, phosphate buffer $\mathrm{pH}$ of 7.4 maintained at $37 \pm 1^{\circ} \mathrm{C}$ in Franz diffusion cell. The rpm of the magnetic bead was maintained at $50 \mathrm{rpm} .2 \mathrm{ml}$ of the sample was withdrawn at predetermined intervals, and the samples were analyzed for the drug content by UV-spectrophotometer at $320 \mathrm{~nm}$. An equal volume of the diffusion medium was replaced in the receiver compartment after each withdrawal to maintain sink condition. Three trials were carried out for all formulations. From the data obtained, the percentage cumulative drug release was calculated and plotted against the function of time to study the pattern of drug release [11].

\section{Drug content}

About $0.2 \mathrm{ml}$ of drug-loaded SLNs was added into $5 \mathrm{ml}$ of methanol in the centrifuge tube. The solution was vortexed for $10 \mathrm{~min}$ and then centrifuged at $5000 \mathrm{rpm}$ for $30 \mathrm{~min}$. The supernatant was collected. The drug content in the supernatant was analyzed by UV-spectrophotometer for $\mathrm{TZ}$ at $319 \mathrm{~nm}[11]$.

Drug content was calculated using the following formula.

$$
\% \text { Drug content }=\frac{\text { Practical amount of drug obtained }}{\text { Theoretical amount of drug }} \times 100
$$

\section{Percentage drug entrapment efficiency}

About $2 \mathrm{ml}$ of SLNs loaded with TZ was placed in the outer chamber of the Centrisart device, and the sample recovery chamber was placed

Table 1: Composition of TZ loaded SLNs containing different lipids and surfactants

\begin{tabular}{|c|c|c|c|c|c|c|c|c|c|}
\hline Formulation code & Formulation no. & TZ mg & CM mg & TS mg & GMS mg & TW mg & PL mg & SL mg & DW ml \\
\hline TZ-SLN-CM-TW 25 & $\mathrm{~F}_{1}$ & 10 & 50 & - & - & 25 & - & 25 & 10 \\
\hline TZ-SLN-CM-PL ${ }_{25}^{25}$ & $\mathrm{~F}_{2}$ & 10 & 50 & - & - & - & 25 & 25 & 10 \\
\hline TZ-SLN-CM-TW & $\mathrm{F}_{3}^{2}$ & 10 & 100 & - & - & 50 & - & 50 & 10 \\
\hline TZ-SLN-CM-TW & $\mathrm{F}_{4}^{3}$ & 10 & 200 & - & - & 100 & - & 100 & 10 \\
\hline TZ-SLN-CM-TW & $\mathrm{F}_{5}$ & 10 & 150 & - & - & 75 & - & 75 & 10 \\
\hline TZ-SLN-CM-PL ${ }_{75}$ & $\mathrm{~F}_{6}^{5}$ & 10 & 150 & - & - & - & 75 & 75 & 10 \\
\hline TZ-SLN-TS-TW 75 & $\mathrm{~F}_{7}^{6}$ & 10 & - & 150 & - & 75 & - & 75 & 10 \\
\hline TZ-SLN-GMS-TW & $\mathrm{F}_{9}^{8}$ & 10 & - & - & 150 & 75 & - & 75 & 10 \\
\hline TZ-SLN-GMS-PL ${ }_{75}$ & $\mathrm{~F}_{10}^{9}$ & 10 & - & - & 150 & - & 75 & 75 & 10 \\
\hline TZ-SLN-TS-PL $_{75}{ }^{75}$ & $\mathrm{~F}_{11}^{10}$ & - & - & 150 & - & - & 75 & 75 & 10 \\
\hline
\end{tabular}

${ }^{*} \mathrm{~F}_{11}$ is a blank formulation. TZ: Tizanidine hydrochloride, CM: Compritol, TS: Tristearin, GMS: Glyceryl monostearate, TW: Tween, PL: Poloxamer, SL: Soy lecithin

Table 2: Interpretation of Fourier-transform infrared spectroscopy studies

\begin{tabular}{|c|c|c|c|}
\hline Compound Name & Type of vibration & Characteristic absorption $\left(\mathrm{cm}^{-1}\right)$ & Observed peak $\left(\mathrm{cm}^{-1}\right)$ \\
\hline \multirow[t]{6}{*}{$\mathrm{TZ}$} & Secondary amine N-H stretch & $3100-3500$ & 3246.31 \\
\hline & Aromatic C-H stretch & $3000-3100$ & 3074.63 \\
\hline & $\mathrm{C}=\mathrm{C}$ aromatic ring stretch & 1600 and 1475 & 1606.76 and 1473.66 \\
\hline & Secondary amine C-N stretch & $1100-1300$ & 1188.19 \\
\hline & Aromatic C-Cl stretch & $1035-1100$ & 1068.6 \\
\hline & Ring bending & Strong peak near 700 & 709.83 \\
\hline \multirow[t]{5}{*}{$\mathrm{TZ}$ and tristearin } & Secondary amine N-H stretch & $3100-3500$ & 3244.38 \\
\hline & $\mathrm{C}=\mathrm{C}$ aromatic ring stretch & 1600 and 1475 & 1606.76 and 1465.95 \\
\hline & Secondary amine C-N stretch & $1100-1300$ & 1174.69 \\
\hline & Aromatic $\mathrm{C}$-Cl stretch & $1035-1100$ & 1068.6 \\
\hline & Ring bending & Strong peak near 700 & 709.83 \\
\hline \multirow[t]{5}{*}{ TZ and Compritol } & Secondary amine N-H stretch & $3100-3500$ & 3246.31 \\
\hline & Aromatic C-H stretch & $3000-3100$ & 3074.63 \\
\hline & $\mathrm{C}=\mathrm{C}$ aromatic ring stretch & 1600 and 1475 & 1606.76 and 1469.81 \\
\hline & Secondary amine C-N stretch & $1100-1300$ & 1192.05 \\
\hline & Ring bending & Strong peak near 700 & 711.76 \\
\hline \multirow[t]{6}{*}{ TZ and glyceryl monostearate } & Secondary amine N-H stretch & $3100-3500$ & 3246.31 \\
\hline & Aromatic C-H stretch & $3000-3100$ & 3074.63 \\
\hline & $\mathrm{C}=\mathrm{C}$ aromatic ring stretch & 1600 and 1475 & 1606.76 and 1471.74 \\
\hline & Secondary amine C-N stretch & $1100-1300$ & 1182.4 \\
\hline & Aromatic $\mathrm{C}-\mathrm{Cl}$ stretch & $1035-1100$ & 1068.6 \\
\hline & Ring bending & Strong peak near 700 & 709.83 \\
\hline
\end{tabular}

TZ: Tizanidine hydrochloride 

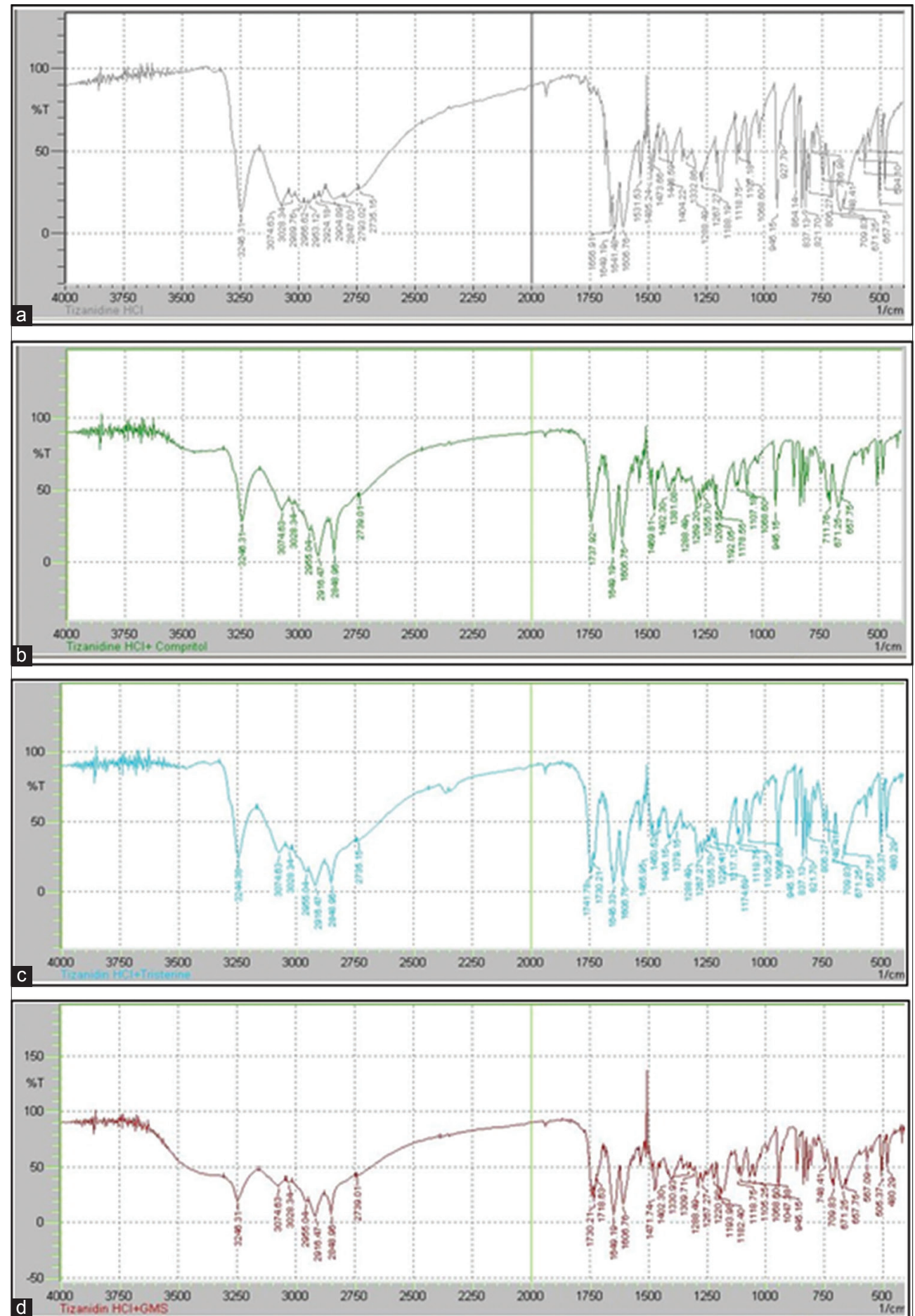

Fig. 1: Fourier-transform infrared spectroscopy spectra of (a) tizanidine hydrochloride, (b) physical mixture of drug and Compritol, (c) physical mixture of drug and tristearin, (d) physical mixture of drug and glyceryl monostearate

on the top of the sample. The unit was centrifuged at $5000 \mathrm{rpm}$ for $20 \mathrm{~min}$. The SLNs along with the encapsulated drug remained in the outer chamber, and the aqueous phase was moved into the sample recovery chamber through filter membrane (molecular weight cutoff 20,000 Daltons). The resulting aqueous phase was analyzed by UVspectrophotometer for $\mathrm{TZ}$ at $320 \mathrm{~nm}$. The entrapment efficiency was calculated using the following relationship [12].

$$
\% \text { Entrapment efficiency }=\frac{\begin{array}{c}
\text { Total amt of drug }- \\
\text { amt of drug in aq. phase }
\end{array}}{\text { Total amt of drug }} \times 100
$$

Particle size analysis

The particle size was determined by dynamic light scattering (DLS), using a Malvern System, with vertically polarized light supplied by an argon-ion laser (Cyonics) operated at $40 \mathrm{~mW}$. Experiments were performed at a temperature of $25.0 \pm 0.1^{\circ} \mathrm{C}$ at a measuring angle of $90^{\circ}$ to the incident beam [13]

\section{Zeta potential}

Zeta potential was measured using Malvern Zetasizer. Nanoparticles were diluted with distilled water and placed in a clear disposable zeta cell at $25^{\circ} \mathrm{C}$. The sample was subjected to three zeta runs to determine both size and potential [14]. 


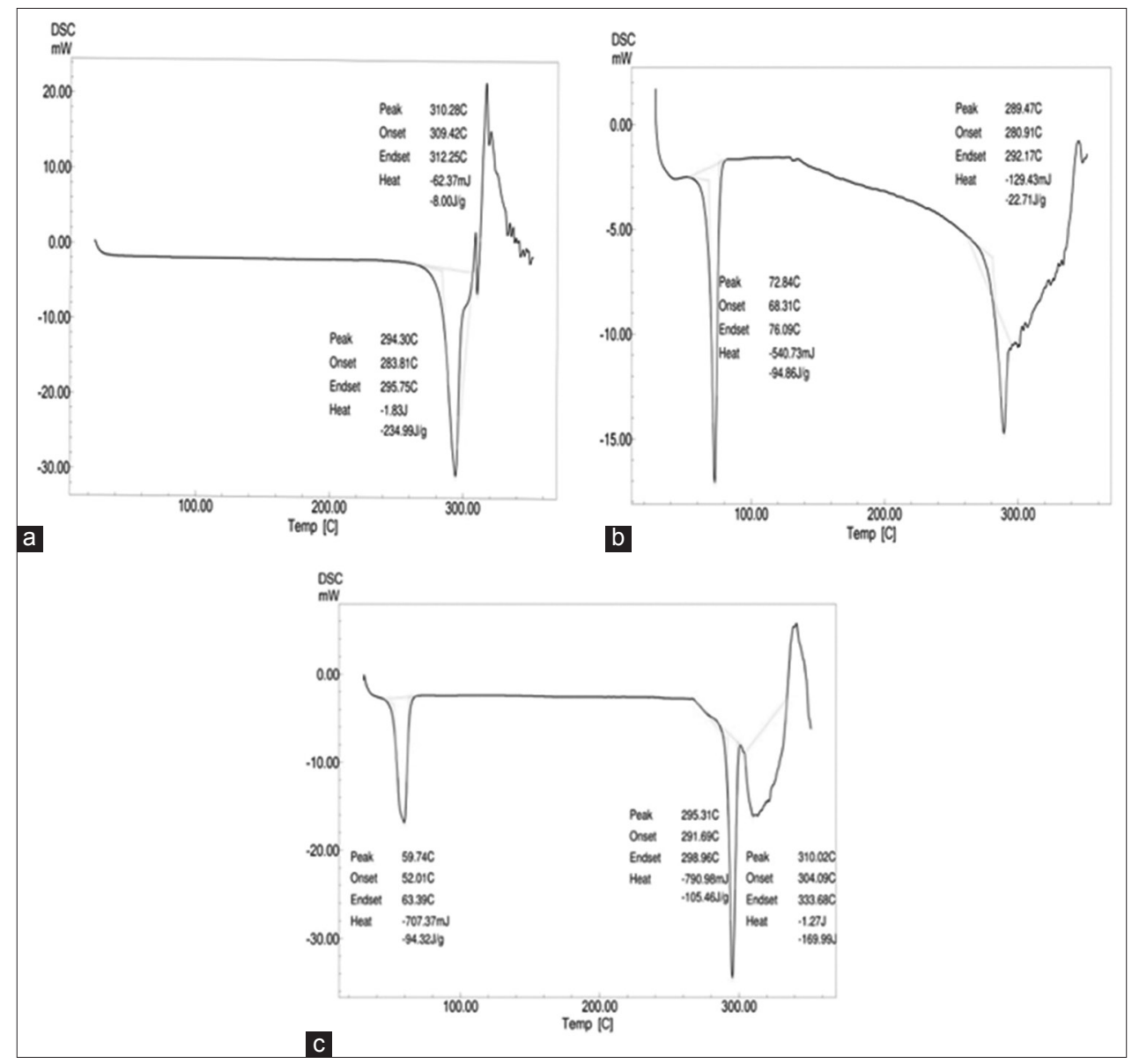

Fig. 2: Differential scanning calorimetry thermogram of (a) tizanidine hydrochloride, (b) physical mixture of drug and Compritol, (c) a physical mixture of drug and tristearin

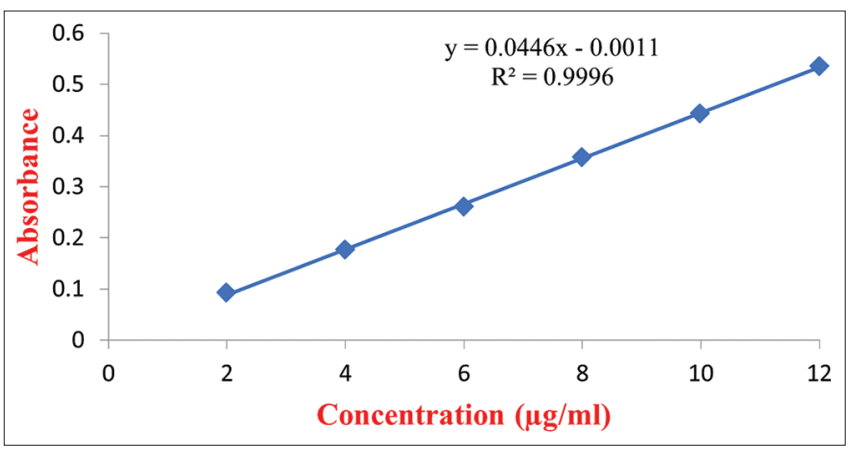

Fig. 3: Standard graph of tizanidine hydrochloride in phosphate buffer of $\mathrm{pH}-7.4$

\section{Polydispersity index (PDI)}

In light scattering, the term polydispersity and \% polydispersity are derived from the PDI; a parameter calculated from a cumulants analysis of the DLS-measured intensity autocorrelation function. Particle size, zeta potential, and PDI are determined by the same instrument, i.e., Malvern Zetasizer [14].

\section{Kinetic modeling of drug dissolution profiles [15]}

The results of in vitro release profile obtained for all the formulations were plotted in models of data treatment and are as follows:

1. Zero-order kinetic model - cumulative $\%$ drug released versus time

2. First-order kinetic model - log cumulative percentage drug remaining versus time

3. Higuchi's model - cumulative percentage drug released versus square root of time
Table 3: Percentage of cumulative drug release of $F_{1}-F_{4}$ formulations $(n=3)$

\begin{tabular}{lllll}
\hline \multirow{2}{*}{ Time $\mathbf{h}$} & \multicolumn{4}{l}{ Percentage of cumulative drug release } \\
\cline { 2 - 5 } & $\mathbf{F}_{\mathbf{1}}$ & $\mathbf{F}_{\mathbf{2}}$ & $\mathbf{F}_{3}$ & $\mathbf{F}_{4}$ \\
\hline 0.5 & $13.45 \pm 1.2$ & $17.2 \pm 2.81$ & $17.29 \pm 2.37$ & $10.9 \pm 2.49$ \\
1.0 & $17.07 \pm 0.5$ & $25.39 \pm 1.18$ & $28.95 \pm 1.79$ & $13.49 \pm 1.98$ \\
1.5 & $37.65 \pm 1.3$ & $47.89 \pm 1.73$ & $38.6 \pm 1.81$ & $13.53 \pm 3.07$ \\
2.0 & $52.21 \pm 2.4$ & $62.14 \pm 2.71$ & $43.5 \pm 3.81$ & $14.63 \pm 2.18$ \\
3.0 & $68.87 \pm 1.8$ & $68.19 \pm 3.91$ & $53.1 \pm 2.73$ & $18.71 \pm 1.46$ \\
4.0 & $71.01 \pm 2.1$ & - & $61.8 \pm 3.45$ & $21.19 \pm 2.85$ \\
5.0 & - & - & $69.25 \pm 2.49$ & $25.74 \pm 3.45$ \\
6.0 & - & - & $72.1 \pm 1.87$ & $28.13 \pm 1.09$ \\
12.0 & - & - & - & $32.87 \pm 2.75$ \\
24.0 & - & - & - & $35.28 \pm 1.25$ \\
\hline
\end{tabular}

${ }^{*} \mathrm{~F}_{1}, \mathrm{~F}_{2}, \mathrm{~F}_{3}$ formulations showed a decrease in $\%$ CDR after 4,3 , and $6 \mathrm{~h}$ of diffusion, respectively

4. Korsmeyer equation/Peppas model - log cumulative percentage drug released versus log time.

\section{RESULTS AND DISCUSSION}

\section{Preformulation studies}

Drug-polymer interaction study by FTIR spectrophotometer

The FTIR was performed for the drug (TZ), lipids (CM, TS, and GMS), and physical mixture of drug and lipids (TZ and CM, TZ and TS, and TZ and GMS). Fig. 1 shows the FTIR spectra of pure drug and the mixture of drug and lipids. Interpretation of the spectrum is shown in Table 2. The spectrum shows that there was no interaction between the drug and the lipid. 
Table 4: Percentage of cumulative drug release of $F_{5}-F_{10}$ formulations for $24 h(n=3)$

\begin{tabular}{|c|c|c|c|c|c|c|}
\hline \multirow[t]{2}{*}{ Time in $\mathbf{h}$} & \multicolumn{6}{|c|}{ Percentage of cumulative drug release } \\
\hline & $\mathbf{F}_{5}$ & $F_{6}$ & $\mathbf{F}_{7}$ & $F_{8}$ & $\mathbf{F}_{9}$ & $F_{10}$ \\
\hline 0.5 & $9.63 \pm 1.56$ & $13.04 \pm 0.69$ & $9.96 \pm 0.42$ & $8.18 \pm 2.17$ & $13.75 \pm 2.60$ & $17.65 \pm 2.80$ \\
\hline 1.0 & $14.21 \pm 1.41$ & $20.93 \pm 0.87$ & $13.57 \pm 1.20$ & $11.47 \pm 1.98$ & $22.14 \pm 2.66$ & $26.48 \pm 1.58$ \\
\hline 1.5 & $18.25 \pm 0.85$ & $27.07 \pm 1.87$ & $19.98 \pm 1.57$ & $14.39 \pm 3.14$ & $29.78 \pm 3.03$ & $32.55 \pm 3.45$ \\
\hline 2.0 & $20.94 \pm 0.89$ & $31.23 \pm 1.58$ & $26.74 \pm 2.75$ & $20.09 \pm 3.46$ & $35.42 \pm 3.28$ & $37.48 \pm 4.33$ \\
\hline 3.0 & $27.30 \pm 1.30$ & $37.97 \pm 1.53$ & $37.05 \pm 3.40$ & $27.64 \pm 1.85$ & $44.09 \pm 4.28$ & $42.85 \pm 2.75$ \\
\hline 4.0 & $34.13 \pm 1.47$ & $45.40 \pm 2.40$ & $42.01 \pm 1.59$ & $34.86 \pm 2.45$ & $50.33 \pm 3.07$ & $50.90 \pm 0.80$ \\
\hline 5.0 & $41.55 \pm 1.19$ & $49.92 \pm 3.93$ & $47.25 \pm 2.19$ & $38.79 \pm 1.92$ & $55.02 \pm 2.69$ & $56.45 \pm 2.20$ \\
\hline 6.0 & $45.45 \pm 0.45$ & $55.27 \pm 3.57$ & $52.47 \pm 3.02$ & $41.96 \pm 0.58$ & $61.16 \pm 4.27$ & $75.62 \pm 1.18$ \\
\hline 12.0 & $61.21 \pm 1.51$ & $78.13 \pm 1.52$ & $69.68 \pm 2.15$ & $63.79 \pm 3.14$ & $66.14 \pm 5.09$ & $78.15 \pm 1.55$ \\
\hline 24.0 & $69.46 \pm 3.03$ & $82.28 \pm 1.42$ & $74.33 \pm 1.71$ & $76.47 \pm 1.56$ & $68.45 \pm 3.84$ & $83.98 \pm 4.93$ \\
\hline
\end{tabular}

${ }^{*} \mathrm{~F}_{10}$ formulation showed the highest $\% \mathrm{CDR}$ and $\mathrm{F}_{9}$ formulation showed the lowest $\% \mathrm{CDR}$

Table 5: Entrapment efficiency and drug content of all formulations

\begin{tabular}{|c|c|c|c|c|c|}
\hline \multirow[t]{2}{*}{ F. No. } & \multirow[t]{2}{*}{ Formulation code } & \multicolumn{2}{|c|}{ Amount of tizanidine hydrochloride } & \multirow{2}{*}{$\begin{array}{l}\text { Entrapment } \\
\text { efficiency (\%) }\end{array}$} & \multirow{2}{*}{$\begin{array}{l}\text { The drug content } \\
\text { in percentage }\end{array}$} \\
\hline & & In aqueous phase (mg) & In lipid phase (mg) & & \\
\hline $\mathrm{F}_{1}$ & TZ-SLN-CM-TW ${ }_{25}$ & 6.55 & 3.45 & 34.50 & 84.50 \\
\hline $\mathrm{F}_{2}$ & TZ-SLN-CM-PL ${ }_{25}^{25}$ & 6.18 & 3.82 & 38.20 & 88.32 \\
\hline $\mathrm{F}_{3}^{2}$ & TZ-SLN-CM-TW $_{50}$ & 6.42 & 3.58 & 35.80 & 79.20 \\
\hline $\mathrm{F}_{4}^{3}$ & TZ-SLN-CM-TW & 4.35 & 5.65 & 56.50 & 94.35 \\
\hline $\mathrm{F}_{5}^{4}$ & TZ-SLN-CM-TW & 2.88 & 7.12 & 71.20 & 80.40 \\
\hline $\mathrm{F}_{6}^{5}$ & TZ-SLN-CM-PL ${ }_{75}^{75}$ & 3.42 & 6.58 & 65.80 & 91.76 \\
\hline $\mathrm{F}_{7}^{6}$ & TZ-SLN-TS-TW $_{75}^{75}$ & 3.18 & 6.82 & 68.20 & 96.12 \\
\hline $\mathrm{F}_{8}^{7}$ & TZ-SLN-TS-PL ${ }_{75}^{75}$ & 2.77 & 7.23 & 72.30 & 98.71 \\
\hline$F_{9}^{8}$ & TZ-SLN-GMS-TW $_{75}$ & 2.72 & 7.28 & 72.80 & 97.49 \\
\hline $\mathrm{F}_{10}^{9}$ & TZ-SLN-GMS-PL ${ }_{75}^{75}$ & 2.50 & 7.50 & 75.00 & 96.85 \\
\hline
\end{tabular}

TZ: Tizanidine hydrochloride, SLN: Solid lipid nanoparticle, GMS: Glyceryl monostearate, TW: Tween, PL: Poloxamer

\section{DSC studies}

The thermal measurement of pure TZ and physical mixture of TZ and CM, TZ and TS were carried out using DSC. The pure drug TZ showed a peak at $294.3^{\circ} \mathrm{C}$. In a physical mixture of TZ and CM, TZ showed a peak at $289.47^{\circ} \mathrm{C}$. In a physical mixture of TZ and TS, TZ showed a peak at $295.31^{\circ} \mathrm{C}$. It shows that the drug is stable with different lipids at different conditions. (Fig. 2 shows the DSC curve of pure drug and the mixture of drug and TS).

Preparation of standard graph of TZ in phosphate buffer of pH-7.4 Calibration curve of TZ was determined using a phosphate buffer of $\mathrm{pH} 7.4$ at $320 \mathrm{~nm}$. The regression was found to be 0.9996 (Fig. 3 shows the standard graph).

\section{Release studies}

The drug release from the nanoparticles was studied by Franz diffusion method. The cumulative percentage release of $\mathrm{TZ}$ from different TZ nanoparticles varied from $35.28 \%$ to $83.98 \%$ depending on the drug, surfactant, and the type of lipid used. Tables 3 and 4 show the percentage of cumulative drug release of all the formulations.

The experiment showed that the drug release from $\mathrm{F}_{1}$ to $\mathrm{F}_{4}$ formulations was not sustained for $24 \mathrm{~h}$ and formulations containing $150 \mathrm{mg}$ of lipid sustained the drug release for $24 \mathrm{~h}$ and showed maximum drug release.

\section{Entrapment efficiency and drug content}

The entrapment efficiency of TZ loaded SLNs was determined by measuring the concentration of un-entrapped drug in an aqueous medium by centrifugation method using Centrisart device. The formulations containing $150 \mathrm{mg}$ of lipid showed good entrapment efficiency. Results of entrapment efficiency and drug content are mentioned in Table 5.

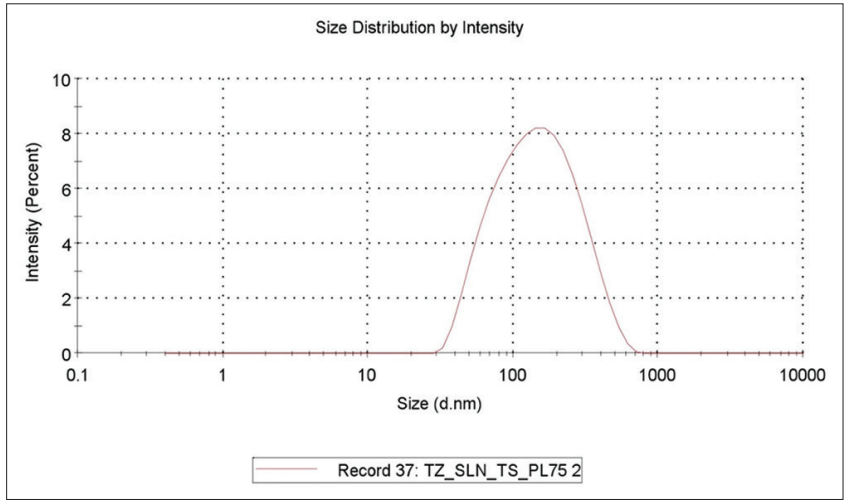

Fig. 4: Size distribution profile of $F_{8}$ formulation

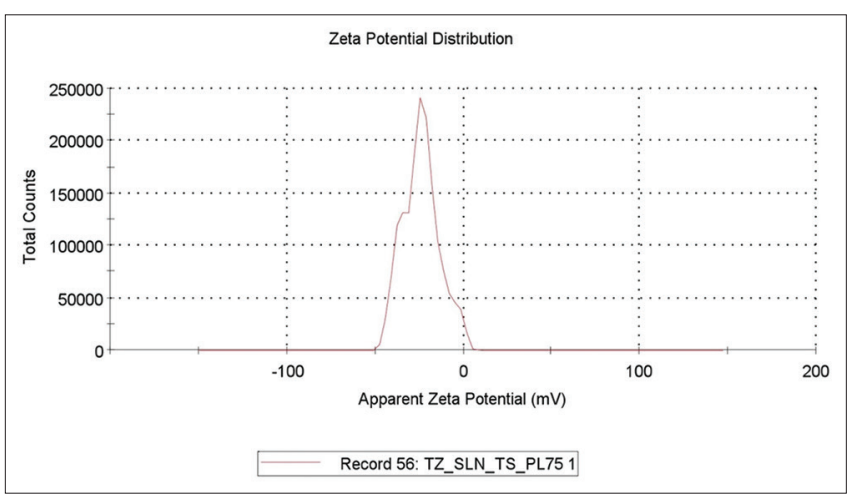

Fig. 5: The zeta potential of $F_{8}$ formulation 
Table 6: The particle size, polydispersity index, and zeta potential of the formulations

\begin{tabular}{|c|c|c|c|c|}
\hline Formulation No. & Formulation code & Particle size $(\mathrm{nm})$ & PDI & Zeta potential $(\mathrm{mV})$ \\
\hline $\mathrm{F}_{5}$ & TZ-SLN-CM-TW & 433.90 & 0.189 & -22.60 \\
\hline $\mathrm{F}_{6}^{5}$ & TZ-SLN-CM-PL & 523.70 & 0.487 & -37.40 \\
\hline $\mathrm{F}_{7}^{6}$ & TZ-SLN-TS-TW $_{75}^{15}$ & 49.70 & 0.204 & -8.85 \\
\hline $\mathrm{F}_{8}^{\prime}$ & TZ-SLN-TS-PL & 119.70 & 0.256 & -23.90 \\
\hline $\mathrm{F}_{9}^{\circ}$ & TZ-SLN-GMS-TW 75 & 97.67 & 0.278 & -30.70 \\
\hline $\mathrm{F}_{10}$ & TZ-SLN-GMS-PL $_{75}$ & 133.00 & 0.279 & -42.00 \\
\hline $\mathrm{F}_{11}$ & TZ-SLN-TS-PL & 108.00 & 0.408 & -15.20 \\
\hline
\end{tabular}

TZ: Tizanidine hydrochloride, SLN: Solid lipid nanoparticle, GMS: Glyceryl monostearate, TW: Tween, PL: Poloxamer

Table 7: The regression values of the tizanidine hydrochloride loaded SLNs

\begin{tabular}{|c|c|c|c|c|c|c|}
\hline \multirow[t]{2}{*}{ Formulation No. } & \multirow[t]{2}{*}{ Formulation code } & \multicolumn{3}{|c|}{ Regression factor } & \multicolumn{2}{|c|}{ Peppas model } \\
\hline & & Zero-order & First-order & Higuchi model & $\mathbf{R}^{2}$ & n value \\
\hline $\mathrm{F}_{5}$ & TZ-SLN-CM-TW & 0.8095 & 0.9026 & 0.9463 & 0.9748 & 0.5493 \\
\hline $\mathrm{F}_{6}^{5}$ & TZ-SLN-CM-PL ${ }_{75}$ & 0.7802 & 0.8917 & 0.9309 & 0.9692 & 0.4926 \\
\hline $\mathrm{F}_{7}^{6}$ & TZ-SLN-TS-TW $_{75}^{75}$ & 0.7341 & 0.8529 & 0.9036 & 0.9412 & 0.5699 \\
\hline $\mathrm{F}_{8}^{\prime}$ & TZ-SLN-TS-PL & 0.862 & 0.9603 & 0.9724 & 0.9766 & 0.6277 \\
\hline $\mathrm{F}_{9}^{8}$ & TZ-SLN-GMS-TW & 0.5712 & 0.6713 & 0.7823 & 0.8896 & 0.4279 \\
\hline $\mathrm{F}_{10}$ & TZ-SLN-GMS-PL ${ }_{75}$ & 0.6701 & 0.7928 & 0.8473 & 0.939 & 0.4261 \\
\hline
\end{tabular}

${ }^{*} \mathrm{R}^{2}$ is the regression factor. TZ: Tizanidine hydrochloride, SLNs: Solid lipid nanoparticles, GMS: Glyceryl monostearate, TW: Tween, PL: Poloxamer

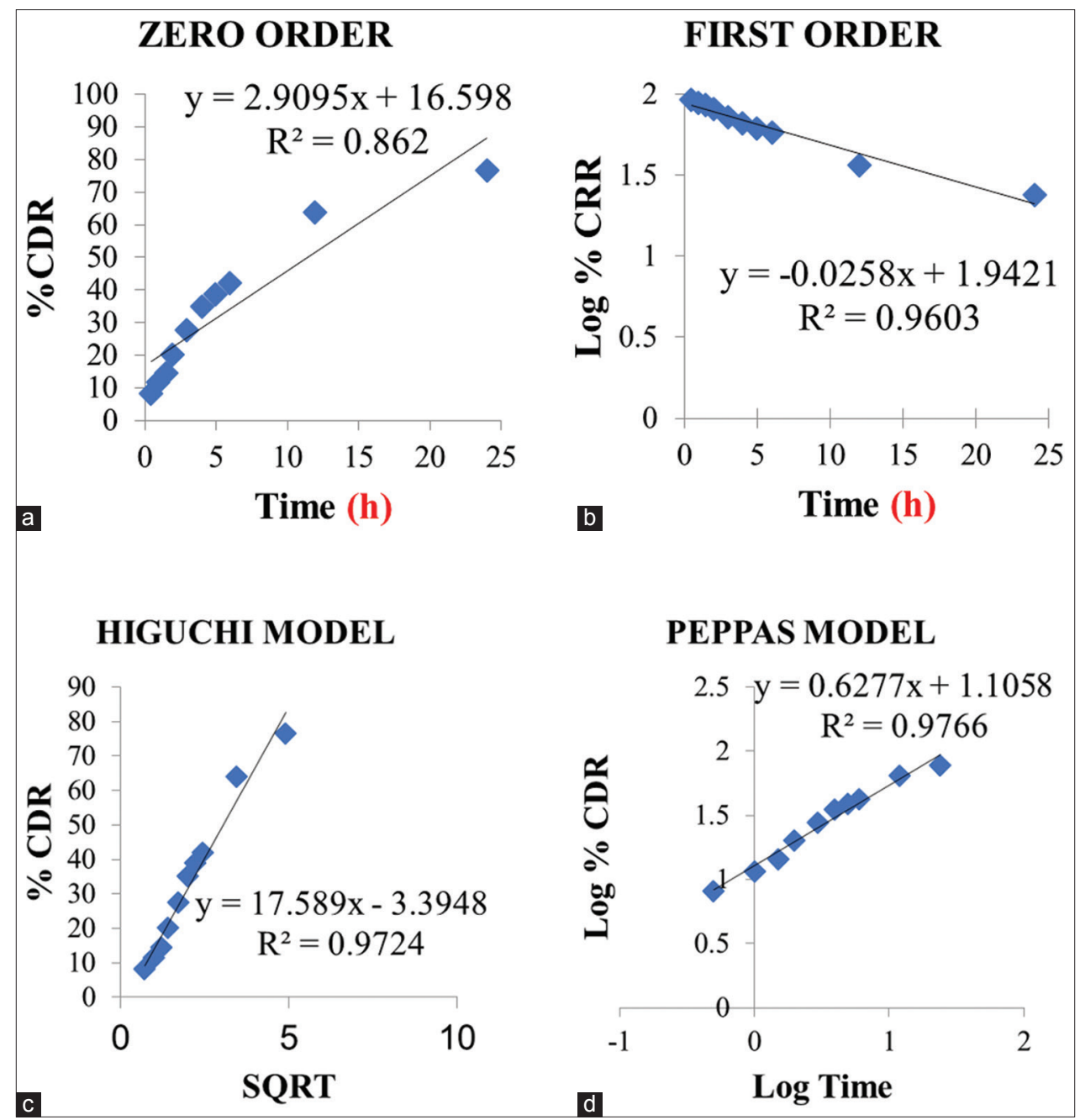

Fig. 6: (a) Zero-order kinetics model of optimized formulation $F_{8}$, (b) first-order kinetics model of optimized formulation $F_{8}$, (c) Higuchi model of optimized formulation $\mathrm{F}_{8}$, (d) Peppas model of optimized formulation $\mathrm{F}_{8}$ 
Among 10 formulations, the $\%$ cumulative drug release of $\mathrm{F}_{1} \mathrm{~F}_{2}, \mathrm{~F}_{3}$, and $\mathrm{F}_{4}$ formulations in $24 \mathrm{~h}$ was not remarkable, and the entrapment efficiency was found to be very low. Hence, these formulations are eliminated from further studies such as particle size analysis, zeta potential, PDI, and release kinetics.

\section{Characterization of nanoparticles \\ Particle size and zeta potential}

Particle size analysis of the TZ SLNs was performed by the Malvern System.

Zeta potential measures the charge on the particles. It allows prediction about the storage stability of colloidal dispersion because of repulsion between the particles. Malvern Zetasizer is the most widely used instrument for the measurement of zeta potential. Table 6 shows the particle size, PDI and zeta potential of $\mathrm{F}_{5}-\mathrm{F}_{11}$ formulations including blank formulation. Figs. 4 and 5 show the particle size distribution and zeta potential of $\mathrm{F}_{8}$ formulation (optimized), respectively.

\section{Release kinetics}

Data obtained from in vitro release studies were fitted to various kinetic equations such as zero-order, first-order, Higuchi model, and Korsmeyer-Peppas model. A model processing of the in vitro release for $\mathrm{F}_{5}-\mathrm{F}_{10}$ formulations is tabulated below. The regression values of the formulations are listed in Table 7. The kinetic models of $\mathrm{F}_{8}$ formulation are shown in Fig. 6

\section{CONCLUSION}

In this study, an attempt was made to formulate TZ SLNs using CM, TS, and GMS as carrier matrices, TW and PL as surfactants, SL as a stabilizer. FTIR and DSC studies were carried out to find out the possible interaction between the selected drug and lipids (CM, TS, and GMS). It revealed that there was no interaction between the selected drug and lipids.

TZ SLNs were prepared by hot homogenization technique. The method was able to produce nanoparticles of acceptable range and stability. All the formulations from $\mathrm{F}_{5}$ to $\mathrm{F}_{10}$ showed high entrapment efficiencies. SLNs were developed by taking three different types of lipids and with two different types of surfactants. Among all batches, in case of TZ_SLN_TS_CL considering their particle size, zeta potential, and in vitro drug release profile.

Size, PDI, and zeta potential of $F_{5}-F_{10}$ formulations developed were in the acceptable and suitable range. The average entrapment efficiency of $\mathrm{F}_{5}-\mathrm{F}_{10}$ formulations was found to $>70 \%$. The release kinetics revealed that the drug release follows first-order kinetics. The release from TZ nanoparticles from the Korsmeyer-Peppas equation indicates that the release mechanism was non-Fickian. Based on the observations, it can be concluded that the formulated lipid nanoparticulate delivery system of TZ using widely accepted and physiologically safe lipids were capable of exhibiting sustained release properties for $24 \mathrm{~h}$. They may be thus used to reduce the frequency of dosing, thereby minimizing the occurrence of side effects, improve bioavailability and increase the effectiveness of the drug.

\section{AUTHORS' CONTRIBUTIONS}

We declare that this work was done by the authors named in this article, and all liabilities pertaining to claims relating to the content of this article will be borne by the authors.

\section{CONFLICTS OF INTEREST}

There are no conflicts of interest.

\section{REFERENCES}

1. Reinholz J, Landfester K, Mailänder V. The challenges of oral drug delivery via nanocarriers. Drug Deliv 2018;25:1694-705.

2. Kushwaha AK, Vuddanda PR, Karunanidhi P, Singh SK, Singh S. Development and evaluation of solid lipid nanoparticles of raloxifene hydrochloride for enhanced bioavailability. Biomed Res Int 2013;2013:584549.

3. Madan JR, Khude PA, Dua K. Development and evaluation of solid lipid nanoparticles of mometasone furoate for topical delivery. Int $\mathrm{J}$ Pharm Investig 2014;4:60-4.

4. Goldspink G, Williams PE. Muscle fiber and connective tissue changes associated with use and disuse. In: Ada A, Canning C, editors. Foundations for Practice. Topics in Neurological Physiotherapy. London: Heinemann; 1992. p. 197-218.

5. Available from: https://www.drugbank.ca/salts/DBSALT000550. [Last accessed on 2019 Apr 12].

6. Gupta R, Bajpai M. Preparation and physicochemical characterization of tizanidine hydrochloride nanoparticles. J Pharm Res 2013;12:15-22.

7. Shakir BS, Manikanta S, Jahnavi T. UV Spectrophotometric determination of rupatadine fumarate in bulk and tablet dosage form by using single-point standardization method. Int J Pharm Pharm Sci 2019;11:120-4.

8. Priyanka S, Shailendra KL. Modified kondagogu gum as matrix-forming material for sustained-release. Int J Curr Pharm Res 2016;8:82-7.

9. Wissing SA, Kayser O, Müller RH. Solid lipid nanoparticles for parenteral drug delivery. Adv Drug Deliv Rev 2004;56:1257-72.

10. Nair R, Kumar AC, Priya VK, Yadav CM, Raju PY. Formulation and evaluation of chitosan solid lipid nanoparticles of carbamazepine. Lipids Health Dis 2012;11:72.

11. Gouda R, Baishya H, Qing Z. Application of mathematical models in drug release kinetics of carbidopa and levodopa ER tablets. J Dev Drugs 2017;6:1-8

12. Cirri M, Maestrini L, Maestrelli F, Mennini N, Mura P, Ghelardini C, et al. Design, characterization and in vivo evaluation of nanostructured lipid carriers (NLC) as a new drug delivery system for hydrochlorothiazide oral administration in pediatric therapy. Drug Deliv 2018;25:1910-21.

13. Rakesh KS, Navneet S, Sudha R, Hosakote GS. Solid lipid nanoparticles as a carrier of metformin for transdermal delivery. Int J Drug Del 2013;5:137-45.

14. Ahmed G, Samar F, Samar S. Design optimization and in vitro evaluation of antifungal activity of nanostructured lipid carriers of tolnaftate. Int J Pharm Pharm Sci 2019;11:109-15.

15. Moawad FA, Ali AA, Salem HF. Nanotransfersomes-loaded thermosensitive in situ gel as a rectal delivery system of tizanidine $\mathrm{HCl}$ : Preparation, in vitro and in vivo performance. Drug Deliv 2017;24:252-60. 